August $1999 \quad \cdot \quad$ NREL/CP-520-26365

\title{
The Growth of Homo-Epitaxial Silicon at Low Temperatures Using Hot Wire Chemical Vapor Deposition
}

J. Thiesen, K.M. Jones, R. Matson, R. Reedy, R. Crandall, E. Iwaniczko, and H. Mahan

Presented at the Materials Research Society's Spring Conference San Francisco, California April 6-10, 1999

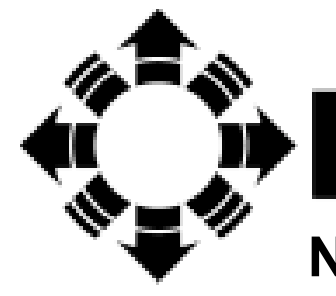

\section{NPEI}

National Renewable Energy Laboratory

1617 Cole Boulevard

Golden, Colorado 80401-3393

NREL is a U.S. Department of Energy Laboratory

Operated by Midwest Research Institute $\bullet$ Battelle $\bullet$ Bechtel

Contract No. DE-AC36-98-G010337 


\section{NOTICE}

This report was prepared as an account of work sponsored by an agency of the United States government. Neither the United States government nor any agency thereof, nor any of their employees, makes any warranty, express or implied, or assumes any legal liability or responsibility for the accuracy, completeness, or usefulness of any information, apparatus, product, or process disclosed, or represents that its use would not infringe privately owned rights. Reference herein to any specific commercial product, process, or service by trade name, trademark, manufacturer, or otherwise does not necessarily constitute or imply its endorsement, recommendation, or favoring by the United States government or any agency thereof. The views and opinions of authors expressed herein do not necessarily state or reflect those of the United States government or any agency thereof.

Available to DOE and DOE contractors from:

Office of Scientific and Technical Information (OSTI)

P.O. Box 62

Oak Ridge, TN 37831

Prices available by calling 423-576-8401

Available to the public from:

National Technical Information Service (NTIS)

U.S. Department of Commerce

5285 Port Royal Road

Springfield, VA 22161

$703-605-6000$ or $800-553-6847$

or

DOE Information Bridge

http://www.doe.gov/bridge/home.html

Printed on paper containing at least $50 \%$ wastepaper, including $20 \%$ postconsumer waste 


\title{
THE GROWTH OF HOMO-EPITAXIAL SILICON AT LOW TEMPERATURES USING HOT WIRE CHEMICAL VAPOR DEPOSITION
}

\author{
J. THIESEN ${ }^{*}$, K.M. JONES, R.MATSON, R. REEDY, E. IWANICZKO, H. MAHAN, R. CRANDALL \\ National Renewable Energy Laboratory (NREL), 1617 Cole Blvd., Golden, CO, 80401 \\ *Also of the Dept. of Electrical Eng., University of Colorado, Boulder, CO
}

\begin{abstract}
We report on the first known growth of high-quality epitaxial $\mathrm{Si}$ via the hot wire chemical vapor deposition (HWCVD) method. This method yields epitaxial Si at the comparatively low temperatures of $195^{\circ}$ to $450^{\circ} \mathrm{C}$, and relatively high growth rates of 3 to $20 \AA / \mathrm{sec}$. Layers up to $4500-\AA$ thick have been grown. These epitaxial layers have been characterized by transmission electron microscopy (TEM), indicating large regions of nearly perfect atomic registration. Electron channeling patterns ( ECPs) generated on a scanning electron microscope (SEM) have been used to characterize, as well as optimize the growth process. Electron beam induced current (EBIC) characterization has also been performed, indicating defect densities as low as $8 \times 10^{4} / \mathrm{cm}^{2}$. Secondary ion beam mass spectrometry (SIMS) data shows that these layers have reasonable impurity levels within the constraints of our current deposition system. Both $\mathrm{n}$ and $\mathrm{p}$-type layers were grown, and $\mathrm{p} / \mathrm{n}$ diodes have been fabricated.
\end{abstract}

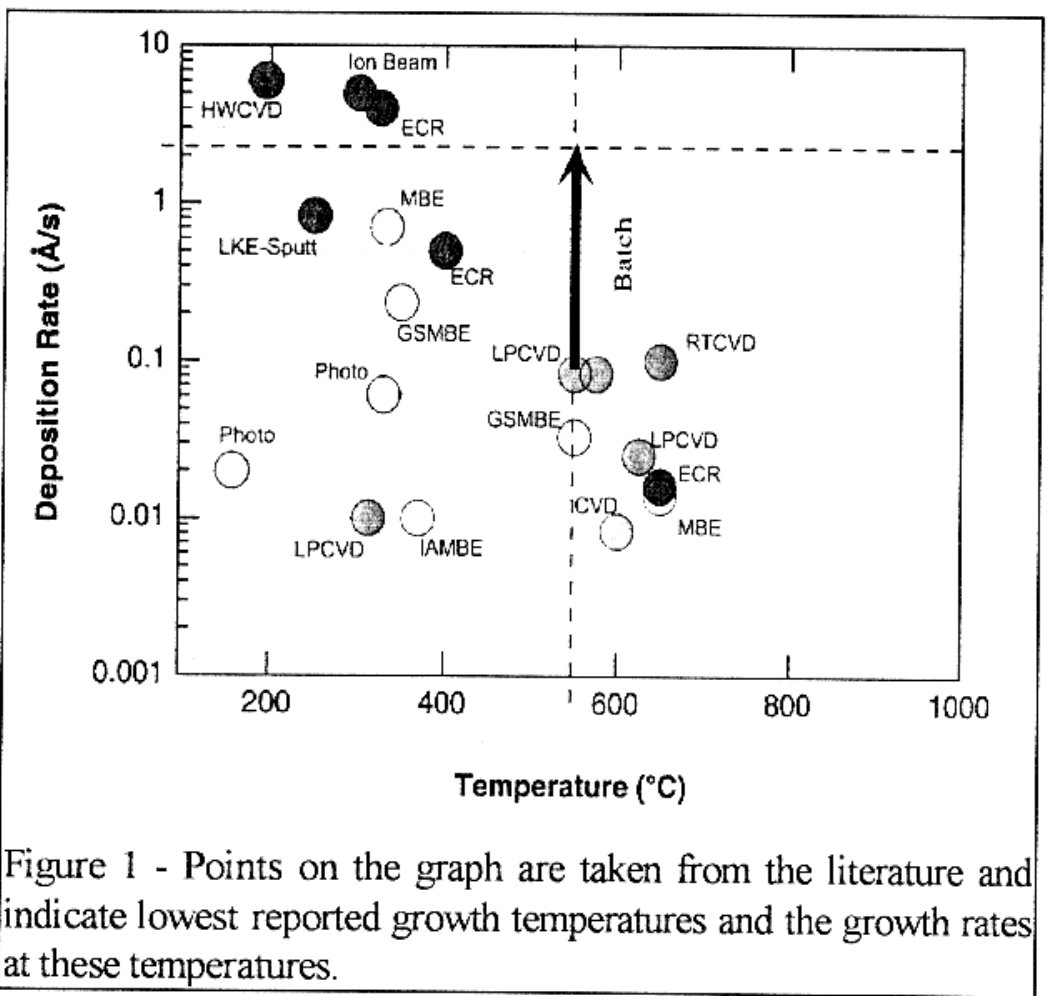

growth temperatures and the respective growth rates for each process ${ }^{1-17}$

\section{Introduction}

The recognized importance of low-temperature silicon epitaxy is clearly reflected by the effort put forth by many distinguished researchers and laboratories, as indicated in Fig $1 .^{1.17} \mathrm{~A}$ lowtemperature epitaxial (LTE) $\mathrm{Si}$ growth process will simplify the process engineering of deep submicron CMOS technology, SiGe alloy devices, and a wide range of novel devices that might be realized through such a growth technique. Recently, NREL researchers discovered that LTE Si can be grown via HWCVD. The initial data indicated that there was some potential in this discovery and this scems to be confirmed in Fig. 1 which shows the reported results from a variety of LTE Si growth techniques, plotting lowest reported There are three main features of this plot that encouraged us to pursue LTE by HWCVD. The vertical dotted line in the center is a somewhat arbitrary cutoff temperature. At this temperature it has been reported that abrupt $\mathrm{P} / \mathrm{N}$ junctions have been grown by the low-pressure chemical vapor deposition (LPCVD) method. Above this point dopant diffusion across a junction can become a problem at long process timcs, so this temperature was chosen as our cut off for LTE. In the center of the graph there is an arrow extending from .086 $\AA / \mathrm{sec}$ to $\sim 2 \AA /$ sec. This arrow originates on the point assigned to a commercial LPCVD process. ${ }^{8}$ Because this 
is a batch process, the arrow represents a multiplication factor of 30 , taking into account the throughput advantage of a batch process when compared to a single wafer process. Fig.l points out that any singlewafer process which is not near the horizontal dashed line at the arrow tip is at a throughput disadvantage

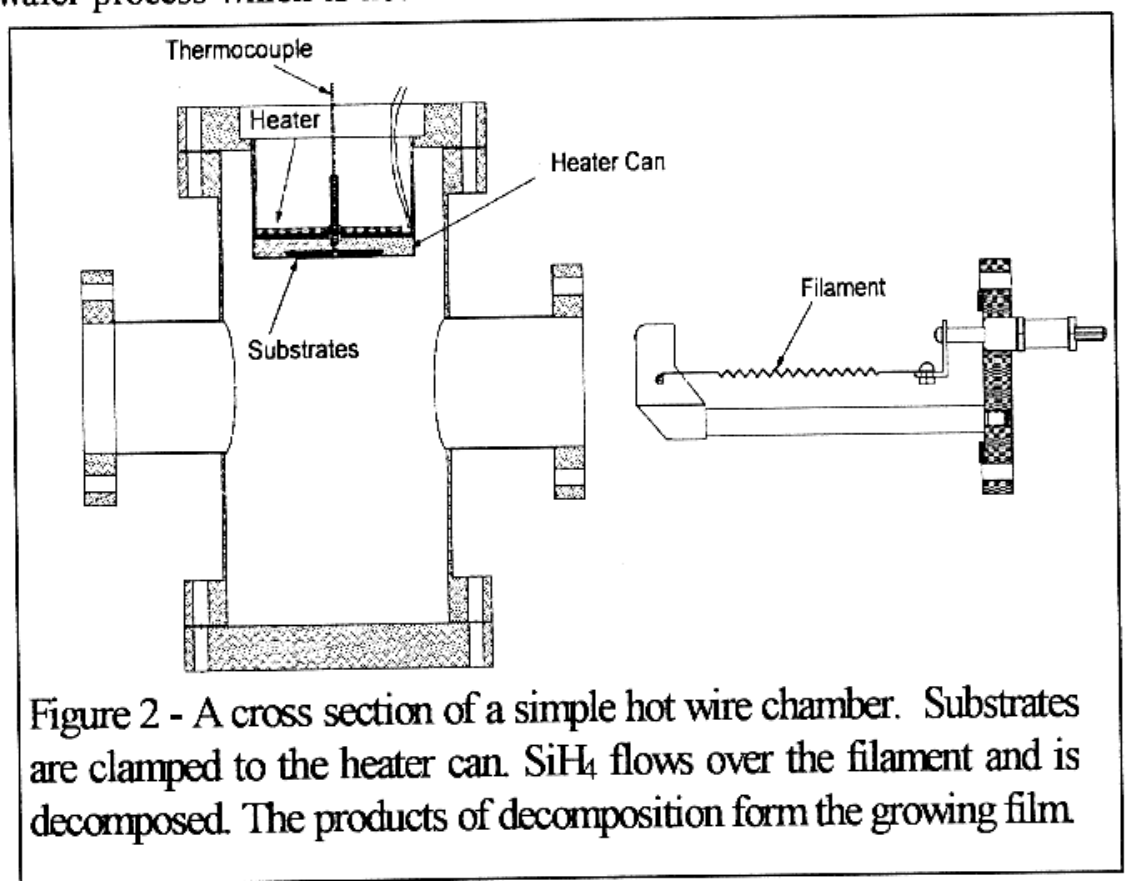

when compared to what is now a commercially viable process. In fact there are only three processes in the square defined by the two dashed lines and the upper left hand corner of the plot. One of these is HWCVD. A fact that explains our interest in this process.

HWCVD is a conceptually simple gas source growth technique. $\mathrm{SiH}_{4}$ is decomposed on a heated filament and the products of decomposition are emitted from the filament with thermal velocities. It is presumed that if the filament temperature is sufficiently high, $\geq 1800^{\circ} \mathrm{C}$, the primary products of decomposition are a $\mathrm{Si}$ atom and $4 \mathrm{H}$ atoms. ${ }^{18,19}$ The produced atomic species in turn react with the remaining $\mathrm{SiH}_{4}$ in the ambient, forming growth species which adsorb onto the substrate surface and condense into a solid $\mathrm{Si}$ layer. $^{18-20}$ Fig. 2 shows a typical HWCVD chamber. Fig. 3 is a indicative of the dominant gas-phase reactions.

Though ostensibly simple, the actual chemistry is quite complex. One of the factors complicating HWCVD is the temperature-dependent chemistry of the filament. It is known that the decomposition of gasphase reactants has an Arrhenius dependence with filament temperature. ${ }^{21}$ It is also known that when

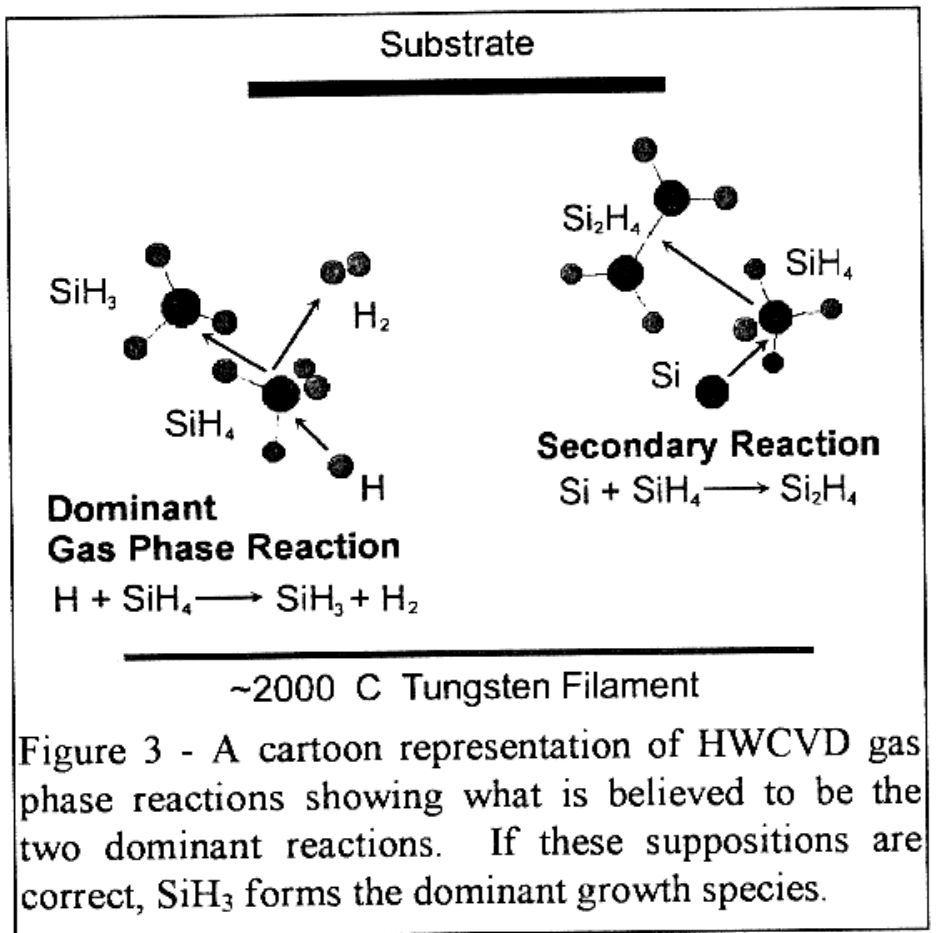
heated in $\mathrm{SiH}_{4}$, the filament ages, changing its chemical properties as a function of time. ${ }^{22}$ At high temperatures this appears to happen rather slowly, on a time scale of hours, while at low temperatures the process can be very fast, a time scale of minutes. The actual aging process seems to be the formation of a WSi alloy, which has the apparent effect of changing filament chemistry and ultimately properties of the $\mathrm{Si}$ layers. Another complication related to filament temperature is the possible evaporation of W or a WSi alloy from the filament surface. To date, SIMS analysis has been unable to detect $\mathrm{W}$ impurities in the films for filament temperatures as high as $2100^{\circ} \mathrm{C}$. However, some groups have reported $\mathrm{W}$ contamination at filament temperatures as low as $1900^{\circ} \mathrm{C}$, so it seems certain that for some temperature, W contamination will become an issue. ${ }^{23}$ 
Like filament chemistry, the gas-phase chemistry of this process has complexities. The nature of the gas-phase chemistry is dominated by the number of collisions that the decomposition species suffer before reaching the substrate and the percentage of those collisions that form growth products. In the tens of $m$ Torr range of pressure, where deposition usually occurs, the number of collisions is typically small, and film properties are sensitive to both the pressure and the filament to substrate distance, or the number of these collisions. It is empirically verifiable that there is an optimum pressure for a given filament to substrate spacing. ${ }^{19}$

Pressure however, has another effect. To first order, pressure may be thought of as proportional to the number of $\mathrm{SiH}_{4}$ atoms that will strike the filament and thus be decomposed. In fact, we have found that the growth rate of epitaxial $\mathrm{Si}$ seems to be proportional to both pressure and flow rate, and this observation leads us to consider the effects of the flow rate on growth. Flow rate is directly proportional to gas velocity and inversely proportional to the residence time, or the average time a molecule will be in the reactor. Flow rate also determines the relative ratio of $\mathrm{SiH}_{4}$ to products in the reactor, or the depletion of the $\mathrm{SiH}_{4}$. At very high depletion's one expects the ratio of $\mathrm{H}_{2} / \mathrm{SiH}_{4}$ to change, with significant consequences to the growth chemistry.

A final complication to epitaxial growth using HWCVD, has to do with the effects that changes in substrate temperature have on the morphology of the growing film. Because our substrates are loaded directly from air into the reactor, we use a H-passivated surface to protect the cleaned Si substrates from oxidation prior to growth. This means that we start with a nominally hydrogen saturated surface. The vacuum desorption spectrum for $\mathrm{H}$ from a (100) $\mathrm{Si}$ surface is well known, ${ }^{24}$ however when there is a large ambient of atomic $\mathrm{H}$, as in HWCVD, there is a strong possibility that the understood desorption spectrum is no longer valid. ${ }^{25}$ In fact we have some evidence that there may be significant changes in the Si surface/H interactions from those observed in vacuum.

The upshot of this introduction to HWCVD epi growth is that the process is complex with many interacting parameters whose exact nature is unknown. We will make reference to various aspects of this introduction as we discuss growth both properties and pathologies related to LTE via HWCVD.

\section{Experimental}

Prior to growth, 1"by 1 " picces of $\mathrm{c}-\mathrm{Si}$ of a chosen doping type are degreased and cleaned using an abbreviated Shiraki method, where the last step has been replaced by SC2 of the RCA clean. ${ }^{26}$ The substrates are left with a final protective oxide until just prior to being loaded into the chamber when they receive a 20 -sec dip in $5 \% \mathrm{HF}$ and a nitrogen blow dry. The wafers are quickly loaded into the reactor and pumped down to a base pressure of about $3 \times 10^{-7}$ torr. When the chamber is at pressure, substrate heating begins. Once at the desired temperature, the filament current is set, and its temperature quickly rises to between $1800^{\circ}$ and $2200^{\circ} \mathrm{C}$. Finally, $\mathrm{SiH}_{4}$ is introduced to the chamber, and the shutter is opened. $\mathrm{SiH}_{4}$ flow rates from 5 to $40 \mathrm{sccm}$ and pressures between 5 and $40 \mathrm{mTorr}$ have all been used at various times. $\mathrm{SiH}_{4}$ is purified using an UltraPure 0100-xl filter, with specified gas contamination levels of $\mathrm{H}_{2} \mathrm{O}, \mathrm{O}_{2}, \mathrm{CO}$, and $\mathrm{CO}_{2}$ less than $10 \mathrm{ppb}$. After deposition is complete, the shutter is closed, all gas flow is stopped, and the chamber is evacuated. If an anneal is desired to reduce hydrogen levels in the film, the substrates are heated to $450^{\circ} \mathrm{C}$ and are in-situ annealed for the desired time. The annealing step is optional and is not responsible for the observed epitaxy. In an experiment to be published later, it has been shown through transmission electron microscopy (TEM) and electron channeling patterns (ECP) that the as-grown samples are indeed epitaxial prior to the anneal.

Characterization methods have included stylus profilometry, ECP analysis, electron beam induced current (EBIC), TEM, and SIMS. ECP and EBIC analysis was performed on a JSM-840 SEM, with a $25 \mathrm{kV}$ beam and a $100 \mu$ spot size. SIMS data were taken on a Camica IMS-5F, sputtered with a $14.5 \mathrm{keV}$ $\mathrm{Cs}$ ion beam, with analysis of the secondary ions. Thin foils for TEM examination were prepared, by dimple polishing and $5 \mathrm{kV} \mathrm{Ar}{ }^{+}$ion milling until electron transparency was achieved. TEM examination was carried out on a Phillips CM-30 TEM operating at $300 \mathrm{keV}$. 


\section{Quality Response Surface}

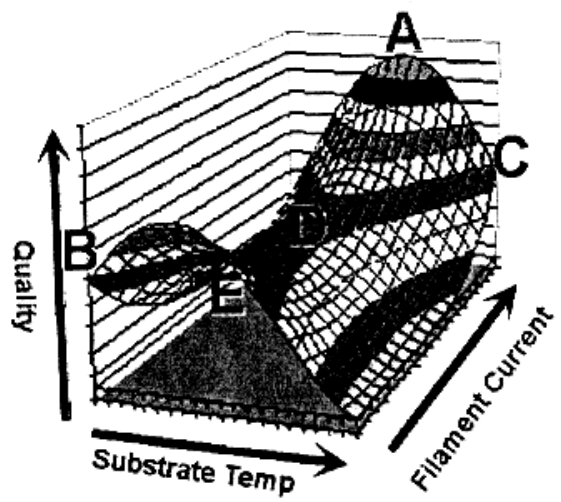

Figure 4 - An ECP derived optimization surface. Varying filament temperature and substrate temperature at a fixed flow rate and pressure, surface indicates predicted changes in crystalline 'quality'. Arrows point in direction of increasing values.

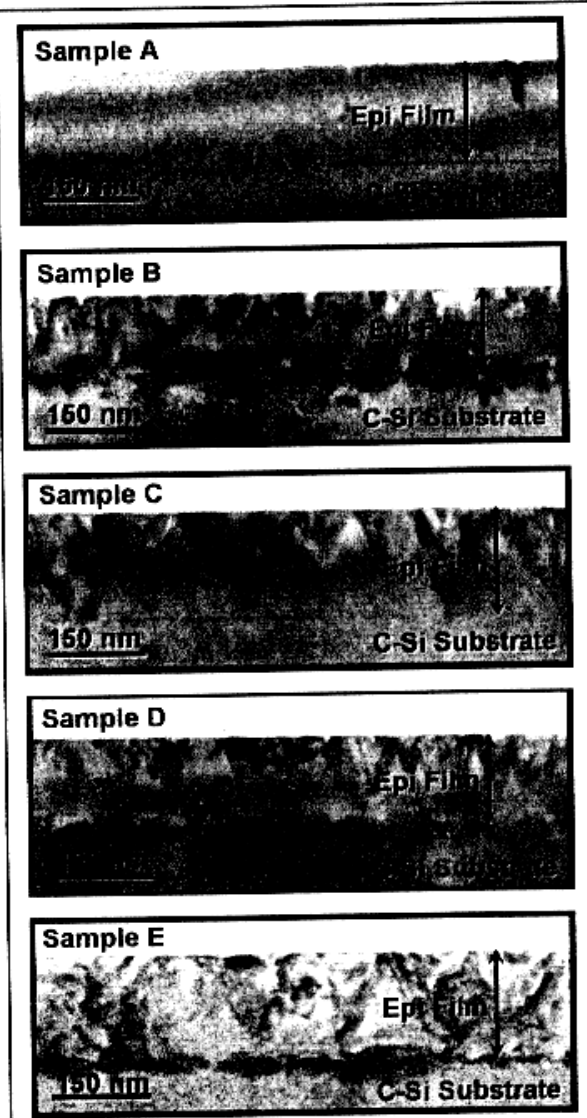

Figure 5 - Cross sectional TEM images corresponding to the indicated values on the surface of figure 4 .

\section{Results and Discussion}

The discussion will present a selection of results pertaining to LTE $\mathrm{Si}$ growth with HWCVD and an accompanying phenomenological analysis. We would like to begin by making some observations regarding the process-optimization results presented earlier in this proceeding. ${ }^{27}$ As indicated above, HWCVD has four basic parameters that control growth: pressure, substrate temperature, flow rate, and filament temperature. In the work presented earlier we have optimized a particular growth process for filament temperature, substrate temperature, and flow rate having previously determined that $11 \mathrm{mTorr}$ was good pressure for film growth over a wide range of other parameters. This optimization was specifically for a nominally intrinsic layer grown on lightly phosphorous doped, $\sim 10^{15}$, n-type, $\mathrm{Si}$. It is important to stress that optimum process conditions appear to vary non-trivially with both dopant levels and the type of dopant in films and substrates. On the other hand, the analysis seems to have general features true for most growths using this technique.

Fig. 4 shows variations in crystalline quality, or the response of a film property, to changes in substrate temperature and filament temperature at a fixed flow rate of $5 \mathrm{sccm}$. The dimension of "quality" refers to a scale from 0-10 of an ECP. A grown layer with an ECP quality of 0 indicates no discernible crystallinity, while an ECP quality of 10 is indistinguishable from a bare piece of $\mathrm{c}-\mathrm{Si}$. For a better description of quality see V2.4 of this symposium. ${ }^{27}$ Fig. 5 is a comparison of various points on the quality response surface with corresponding TEM cross sections. Each cross section is labeled from $A-E$ as are the points on the response surface that correspond to growth conditions for these samples. By comparing TEM images with points on the response surface we can begin to sketch out the physics we seem to be observing

The obvious starting point is sample $\mathrm{A}$, grown at $350^{\circ} \mathrm{C}$, with a $15 \mathrm{~A}$ filament current, and a $5 \mathrm{sccm}$ flow rate. This is clearly the best sample of the five, and as is shown much later in Fig. 11, this sample exhibits very nice atomic registration and defect free growth over a lateral region of $\sim .5 \mu$ and corresponds to the optimum point, 'A', on the surface. Without seeing Fig. 4, one might expect there to be a minimum temperature below which epitaxy fails for a given thickness and above which epitaxy persists. It might therefore seem strange that there is a peaked optimum substrate temperature as indicated in Fig. 4. To study this seeming inconsistency, let us consider Sample C, whose growth conditions differ from those of A only by raising the substrate temperature to $450^{\circ} \mathrm{C}$. Sample C like Sample A, and unlike the rest of the samples, has a relatively strain-free interface; however, unlike sample A, Sample $\mathrm{C}$ is decorated with
we postulate that by raising the substrate temperature, the $\mathrm{H}$ - 
terminated surface has become more reactive, possibly due to the desorption of $\mathrm{H}$, then we might suspect that as growth species arrive, they have an increased probability to form crystalline defects.

This brings out an interesting point. The dominant growth species must have a very high surface mobility for epitaxy to proceed at such low temperatures and such high growth rates. It has been shown elsewhere that for a more reactive species, such as atomic $\mathrm{Si}$, epitaxial growth does not proceed on a $\mathrm{H}$ saturated (100) Si surface. ${ }^{5,28,29}$ On the other hand, we have observed epitaxy at temperatures as low as $200^{\circ} \mathrm{C}$, where presumably just such a surface is stable (Fig. 8). This seems to indicate that indeed the dominant growth species must have a very high surface mobility as well as a low reactivity. This being true, one can imagine that changes in the surface reconstruction and/or the number of unsaturated $\mathrm{Si}$ surface bonds might lead to observed changes in growth morphology.

To further illustrate this point, consider Samples A, D, and E, which were all grown at $350^{\circ} \mathrm{C}$. It is clear that there is significant difference between Sample A and Samples D and E, and that there is even a difference, though slight, between the morphologies of samples D and E. Again, we suggest that this has to do with the changes in surface chemistry. Fig. 6 seems to corroborate this postulate in a somewhat indirect

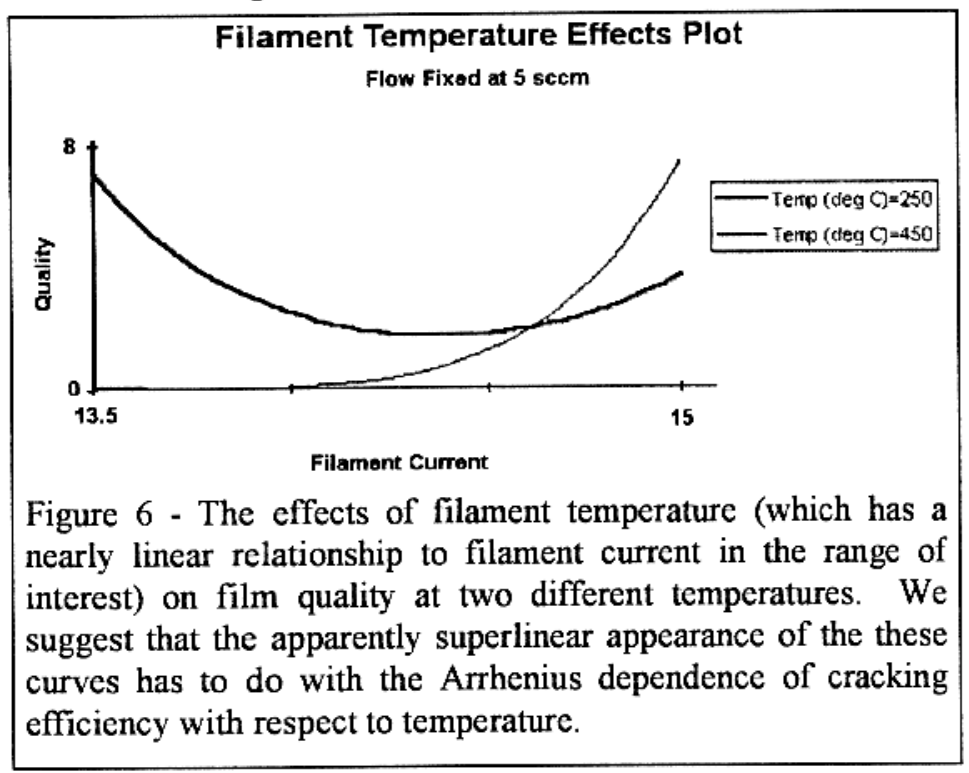

way. We know that over the temperature ranges of interest, the temperature dependence of the filament is nearly linear with filament current. But Fig. 6 seems to indicate that there is a superlinear change in layer quality with filament current. As stated above, we know that the decomposition of gaseous products and thus the production of growth species has an Arrhenius dependence on the $\mathrm{W}$ filament temperature. $^{21}$ To better examine the ramifications of this, we note that Fig. 6 has two curves, one at a substrate temperature of $250^{\circ} \mathrm{C}$ and the other at $450^{\circ} \mathrm{C}$. Let us consider the hightemperature case first.

Knowing that there is a temperature-dependent $\mathrm{H}$ desorption spectrum from a $\mathrm{Si}$ surface in vacuum, we postulate that $\mathrm{H}$ induced changes in the $\mathrm{Si}$ surface caused by this desorption, can affect surface mobilities as has been empirically observed by others. ${ }^{30}$ These changes in surface mobilities might affect the overall growth morphology. If we consider the $\mathrm{H}$ chemical potential $\left(\mu_{H}\right)$, to dominate these changes in surfacestructure, as has been argued elsewhere, ${ }^{25}$ then one might surmise that for a given substrate temperature there exists an optimum gas-phase concentration of atomic $\mathrm{H}$ necessary to maintain the optimum surface, or the optimum mobility/reduced-reactivity of the growth species on this surface. We then expect the steady-state surface-mobility to be functionally dependent upon both substrate temperature and the production of atomic $\mathrm{H}$, or the filament temperature. If this is true, then at elevated temperatures we would need to increase the flux of $\mathrm{H}$ to maintain a proper relationship between the arrival of growth species and their mobility on the surface, possibly explaining the superlinear rise in film quality with filament current in the high temperature case.

The low temperature case is more puzzling and because it seems that this curve might actually be the sum of two superlinear curves, we will examine the high- and low-current extrema of this curve separately. In the case of low-filament current and low substrate temperature we presume that the low-reactivity, $\mathrm{H}$ saturated, surface established just prior to growth is relatively unperturbed. From this starting assumption, we suggest at least two possible causes for the formation of crystalline defects. The first possibility is the introduction of $\mathrm{H}$-induced damage caused by super-saturation of the surface by atomic $\mathrm{H}$, and the other being premature reactions of growth species with each other and/or improper bonding sites caused by the arrival of growth species at rates greater than the rates at which proper bonding is possible. 
The possibility of crystalline defects arising from premature/improper bonding might be explained as a competition between the temperature/H controlled mobility of the surface species and the rate at which growth species will bond improperly, which we might reasonably assume is dependent on the concentration of such species. On the other hand, damage from atomic $\mathrm{H}$ has been observed in many instances. ${ }^{25,31,32}$ It has also been stated and observed, that a dihydride terminated (100) surface is more prone to the formation of defects than other Si surfaces. ${ }^{25,33,34}$ To test this we performed a simple simulation of the (100) $\mathrm{Si}$ surface. Using the MM2 energy minimization as implemented in CambridgeSoft's Chemoffice suite ${ }^{35}$ of molecular-structure analysis tools, we created a (100) Si crystallite of $\sim 800 \mathrm{Si}$ atoms and dressed it up with various $\mathrm{H}$ terminations. The MM2 energy algorithm calculates stored bond energy due to twisting, bending, stretching, and Leonard-Jones potential type interactions. Using this scheme, we verified that the dihydride terminated surface has a definite potential for point-defect and possibly platelet-defect formation on a (100) $1 \times 1$ reconstructed Si surface (Fig. 7). Simulations on this simple system seem to indicate that breaking Si surface back bonds and allowing the system to come to equilibrium can significantly reduce the system energy. If we go so far as to form a platelet-defect, structurally consistent with the observed spectroscopy ${ }^{36}$ and two monolayers deep, we observe that many of the canted $\mathrm{H}$ pairs have relaxed and that the overall system energy has been reduced by $\sim 11 \%$. While this is not a detailed ab-initio calculation, it may provide some intuition into what we and others seem to have observed when excess concentrations of atomic $\mathrm{H}$ impinge on a $\mathrm{H}$-saturated (100) $\mathrm{Si}$ surface. ${ }^{33,34}$ We suspect that this type of $\mathrm{H}$ induced defect provides a nucleation site for other defects in the growing layers.

With these facts in hand, we might expect that for a H-saturated $\mathrm{Si}(100)$ surface, epitaxial quality could rise as the production of growth species declines - the low filament current extrema. We would expect this because the reduction in growth species reduces both the flux of atomic $\mathrm{H}$ at the surface and the arrival rate of growth species at the surface. On the other hand, if we were to increase the production of growth species, we might expect to increase the rate of improper bonding, but we would also increase the $\mathrm{H}$-initiated etching of strained $\mathrm{Si}-\mathrm{Si}$ bonds, this benefit would be accompanied by an expected increase in $\mathrm{H}$-induced damage, possibly explaining why the quality at the high-filament current extrema is reduced with respect to that of the low-filament current case.

Finally, one might ask why the increase in atomic $\mathrm{H}$ at high substrate temperatures does not seem to produce $\mathrm{H}$ damage as we have speculated that it does for low substrate temperatures. We again refer to $\mu_{H}$ and argue that there is a temperature-dominated balance between the effusion, diffusion, and concentration of $\mathrm{H}$ at the surface; balancing between the extremes of a reactive but stable surface and a surface that is less reactive but more prone to defect formation.

Having attributed some of observations to understood $\mathrm{Si} / \mathrm{H}$ physics, we can return to examining the different morphologies observed in A, D, and $\mathrm{E}$. In case $\mathrm{A}$ we are at or near an optimum point of surface mobility versus surface reactivity, and for this set of parameters we produce a layer of reasonable quality. Reducing the filament current to $\sim 14$ amps as in the case $\mathrm{D}$, has reduced the amount of $\mathrm{H}$ production and because the $\mathrm{H}$ terminated surface at $350^{\circ}$ has presumably become more prone to $\mathrm{H}$ desorption, there is no longer enough $\mathrm{H}$ to maintain a low-reactivity surface. We thus observe an increase in defect formation. In sample $\mathrm{E}$, we have further decreased the production of $\mathrm{H}$ and at the same time the arrival rate of growth species. In this case then, despite a more reactive surface, it is possible that the adatoms have time to find more optimum bonding sites, however both samples $\mathrm{D}$ and $\mathrm{E}$ have a high density of interfacial strain fields and a large number of crystalline defects. We should note that on our quality scale of $0-10$, our optimization predicts only a small difference between $\mathrm{E}$ and $\mathrm{D} \sim(1 \pm .5)$, quality units, and the significance of this difference it is not entirely clear from the TEM cross sections.

A final observation with respect to the optimization data answers the question: Why might layer quality fall off as with decreasing temperature for a constant filament current as evidenced in sample B? There would appear to be at least two reasons for this, the first being the atomic $\mathrm{H}$ induced damage argument advanced above, and the second being what appears to be a temperature-limiting thickness. We seem to have noticed that, like other LTE techniques, there appears to be a temperature-dependent thickness limit to epitaxial growth. ${ }^{17}$ This behavior is demonstrated in Fig. 8 where we see 3 films all grown at a substrate temperature of $200^{\circ} \mathrm{C}$, under identical conditions except for the length of growth time. We see in this image 
a steady increase in interfacial strain fields and overall degradation as the layer becomes thicker. In Fig. 8a

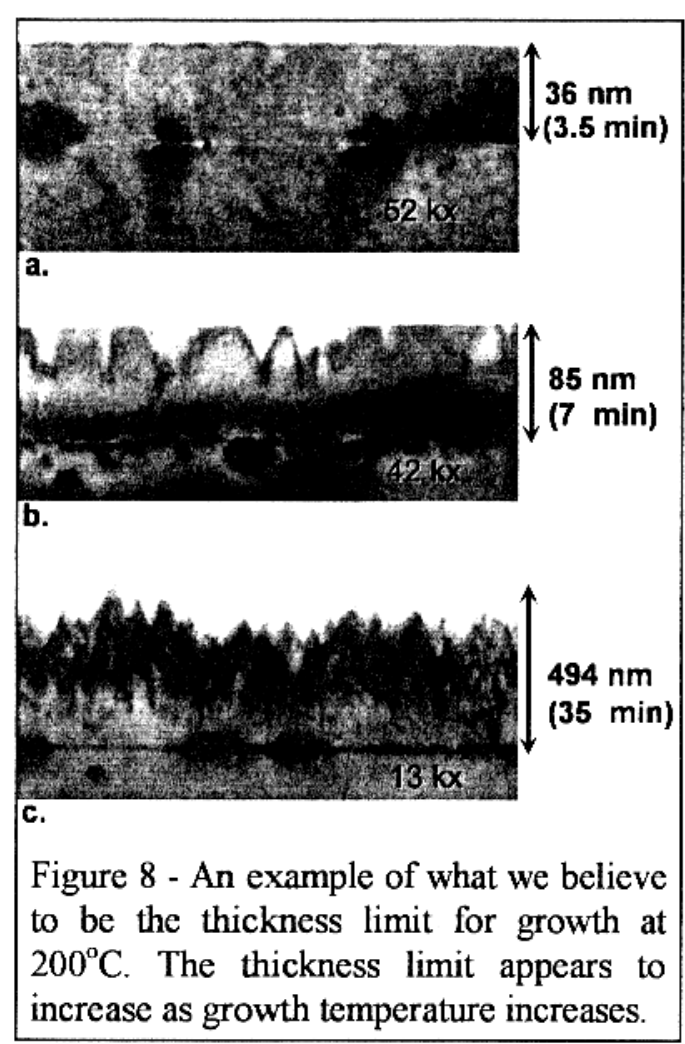
there are a few strain fields, possibly due to contamination or perhaps because the growing film is already nearing the critical thickness, or perhaps because these films were produced with some $\mathrm{H}_{2}$ dilution of the $\mathrm{SiH}_{4}$. Despite these flaws, the layer demonstrates epitaxy throughout the extent of its growth. In Fig. 8b, the interfacial strain fields are exacerbated and we observe v-shaped notches where a-Si has grown and been preferentially etched during the ion milling step of TEM sample preparation. Fig. 8c indicates the complete breakdown of epitaxy, with much of the upper film having been removed due to the same preferential etching. These data might indicate a limiting thickness. We seem to also observe that this thickness limit increases superlinearly as a function of increasing substrate temperature, as has been observed in other cases. ${ }^{17}$ Though possibly coincidental, we have also observed an almost symmetric superlinear decrease in $\mathrm{H}$ concentration with increasing substrate temperature, possibly indicating that thicker films require reductions in $\mathrm{H}$ concentration.

Having used one of our optimization studies to outline a preliminary phenomenological model, we will briefly discuss some related phenomena a crystal grower is likely to encounter when using HWCVD for LTE Si. One of the first that we encountered, was the apparent difference in morphologies between layers grown on $\mathrm{n}$ and $\mathrm{p}$ type substrates. Fig. 9 shows TEM cross sections of two nominally intrinsic layers on substrates prepared identically in every way, and grown simultaneously. The only difference between these layers is that one was grown on n-type, doped with $\mathrm{P}$ at $\sim 10^{18}$, and the other on $\mathrm{p}$-type, doped with $\mathrm{B}$ at $\sim 10^{18}$. This leads us to introduce what we believe is a related issue involving an apparent increase in platelet formation and hydrogen damage when, under some conditions, n-type layers are grown on p-type substrates. Fig. 10 shows one of our first attempts at growing an n-type layer. This Fig. shows a $4500 \AA$ layer of n-type, $\sim 10^{18}$

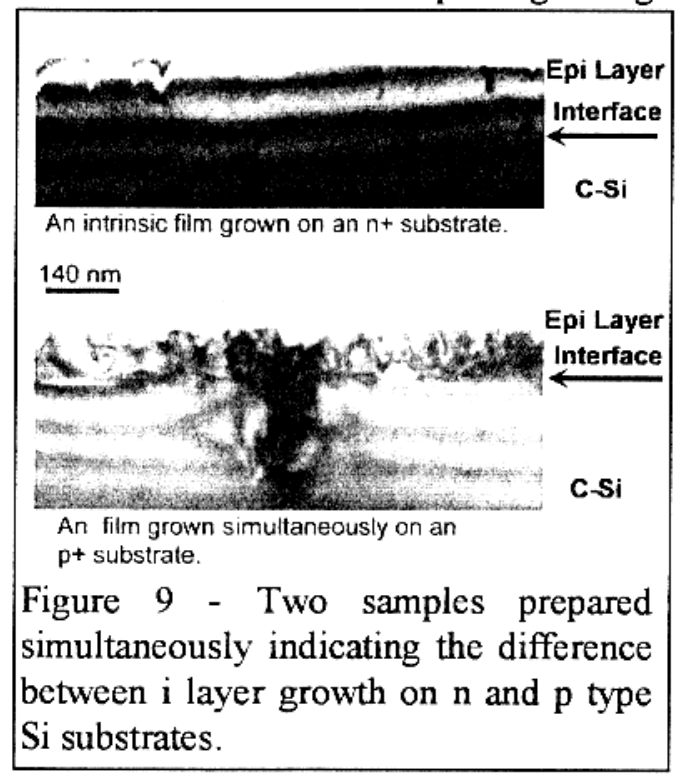

$\mathrm{P}$ doped $\mathrm{Si}$, grown on a p-type substrate doped at $\sim 2 \times 10^{15}$ with B. Grown under conditions ostensibly similar to those of sample $\mathrm{A}$ in Fig. 5 above, we observe what appears to be a definite increase in $\mathrm{H}$ induced damage. Fig. 10 provides two different views of this damage. The view in the lower left is a standard TEM cross section showing a proliferation of stacking faults that have eventually resulted in a-Si growth. This cross section also shows narrow regions where perfect epitaxy is observed across the entire $4500 \AA$ extent. The image in the upper right hand corner is a (220) two beam cross section of the same sample. This image seems to indicate that the origin of the stacking faults are $\mathrm{H}$ platelets. Platelets being identified as the lines running along the (111) planes and surrounded by the strain fields radiating from these lines. Both of the layers in Fig. 9 and Fig. 10 were grown at substrate temperatures above $300^{\circ} \mathrm{C}$ and yet the formation of platelet type defects seems to have persisted, in seeming contradiction to the observations of others. ${ }^{32,36}$ 


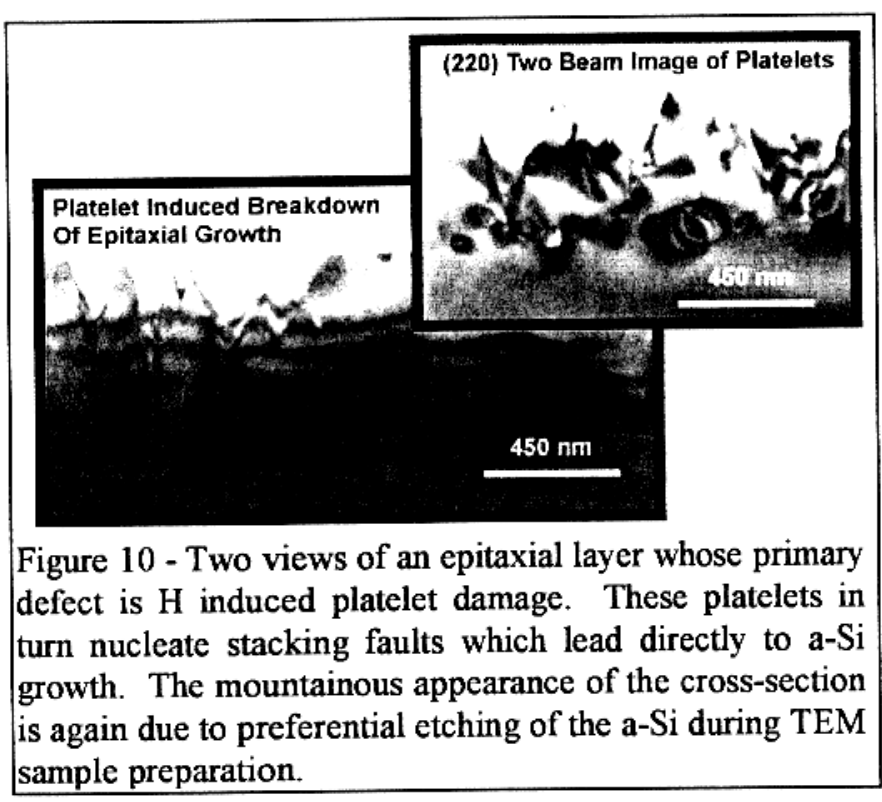

Although these two examples of defective growth were produced under very different conditions, a commonality exists between the layer in Fig. 10 and the layer grown on the ptype substrate in Fig. 9. If we consider the band diagrams of these two samples, we see that in each case the bands bend down rather sharply at the interface between the film and the substrate. We know from elementary semiconductor analysis that when the bands bend down, charge can accumulate, and there seems to be some evidence that in similar cases, associated shifts in the temperature programmed desorption spectrum for the hydrogen terminated (100) Si surfaces have been observed. ${ }^{37}$ It may then be that due to strong band bending and the accumulation of charge, a $\mathrm{H}$ saturated surface is persisting due to enhanced adsorbate bonding, possibly yielding the damage observed in Figs. 9and 10 via previously discussed mechanisms.

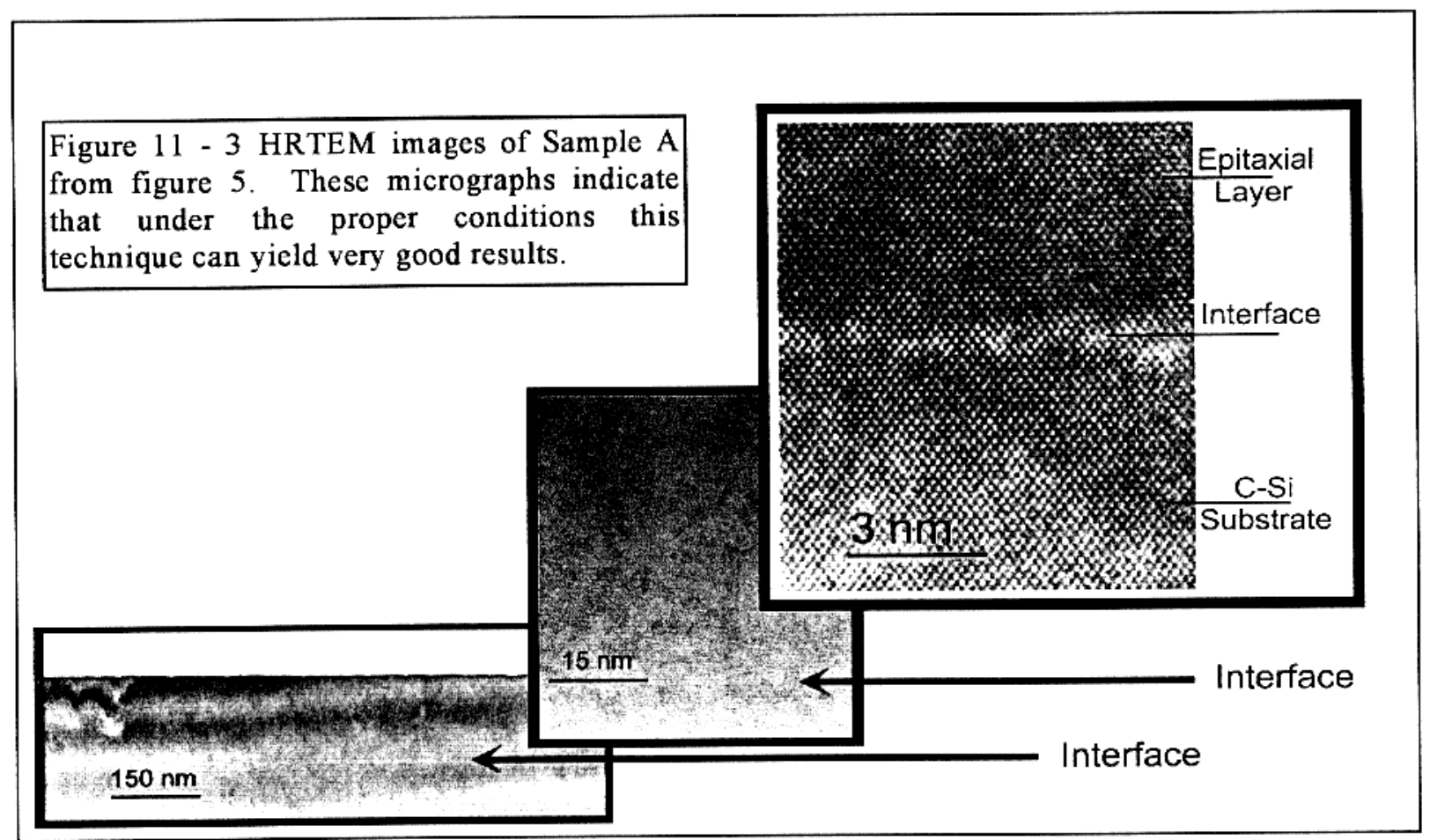

The last item we will discuss before moving on to dopants and other impurities in the films, is to exemplify what is possible under well optimized growth conditions. Fig. 11 above, is one of the better layers we have grown and in fact is a high-resolution TEM image of sample A in Fig. 5 . One reason that this image was chosen is for the clear demarcation between the initial growth surface and the layer, as seen by the trace contamination along the interface. We attribute this trace contamination to cleaning issues we seem to have corrected. More importantly, this layer shows that when properly optimized, epitaxy of high quality can be produced using this technique. This layer, grown at $\sim 350^{\circ} \mathrm{C}$, is $1400 \AA$ thick and with a growth time of $4 \mathrm{~min}$. In this particular case, effective $\mathrm{SiH}_{4}$ utilization was about $10 \%$. The results of this optimization seem to be very reproducible, but it should be noted that when using HWCVD for LTE Si, 
separate optimizations seem to be necessary for growth on different substrate types and for films with different doping levels.

At last, this brings us to the study of doping and other impurities in the films. At present, we have grown epitaxial layers with $10^{18}$ and $10^{19}$ doping levels, and we will comment on these somewhat preliminary results. We seem to have observed that under certain conditions, $\mathbf{P}$ incorporation appears to be greater than the gas stoichiometric level. When flowing $100 \mathrm{ppm} \mathrm{PH}_{3}$ in $\mathrm{He}$ at $1 \mathrm{sccm}$, with $10 \mathrm{sccm} \mathrm{SiH}_{4}$ and a filament current of 14A, SIMS analysis indicates P levels in the film on the order of $2 \times 10^{18}$. These results should however be taken with a grain of salt, as it appears that $\mathbf{P}$ incorporation may be very sensitive to $\mathrm{SiH}_{4}$ depletion or perhaps autodoping. For example, when flowing $\mathrm{PH}_{3}$ at a nominal flow rate of $.07 \mathrm{sccm}$ with a $\mathrm{SiH}_{4}$ flow of $5 \mathrm{sccm}$, and a filament current of $15 \mathrm{~A}$ the measured $\mathrm{P}$ levels have apparently increased to the order of $10^{19}$. It seems that autodoping is a likely culprit when trying to explain these changes in dopant concentration, since dopant incorporation seems to have changed by an order of magnitude while depletion has changed by only a factor of 2 , while prior to this series of growths large concentrations of $\mathrm{PH}_{3}$ were introduced into the chamber.

Our initial efforts at device analysis using this simple $\mathrm{n}$ on $\mathrm{p}$ diode structure, indicate the presence of a rectifying junctions and activated dopants. EBIC analysis on devices made from our best layers has placed defect concentrations at $\sim 8 \times 10^{4} / \mathrm{cm}^{2}$, a limit we may have difficulty overcoming due to the design of our current deposition system. We are presently working on a complete dopant analysis of these layers and should be able to report on these efforts shortly.

In the case of the growth of $\mathrm{B}$ doped $\mathrm{p}$-type films, results are less clear. Initial growths were attempted with a highly concentrated dopant source, $\left(5 \% \mathrm{~B}_{2} \mathrm{H}_{6}\right.$ in $\left.\mathrm{He}\right)$, and these layers, with presumed $\mathrm{B}$ levels of

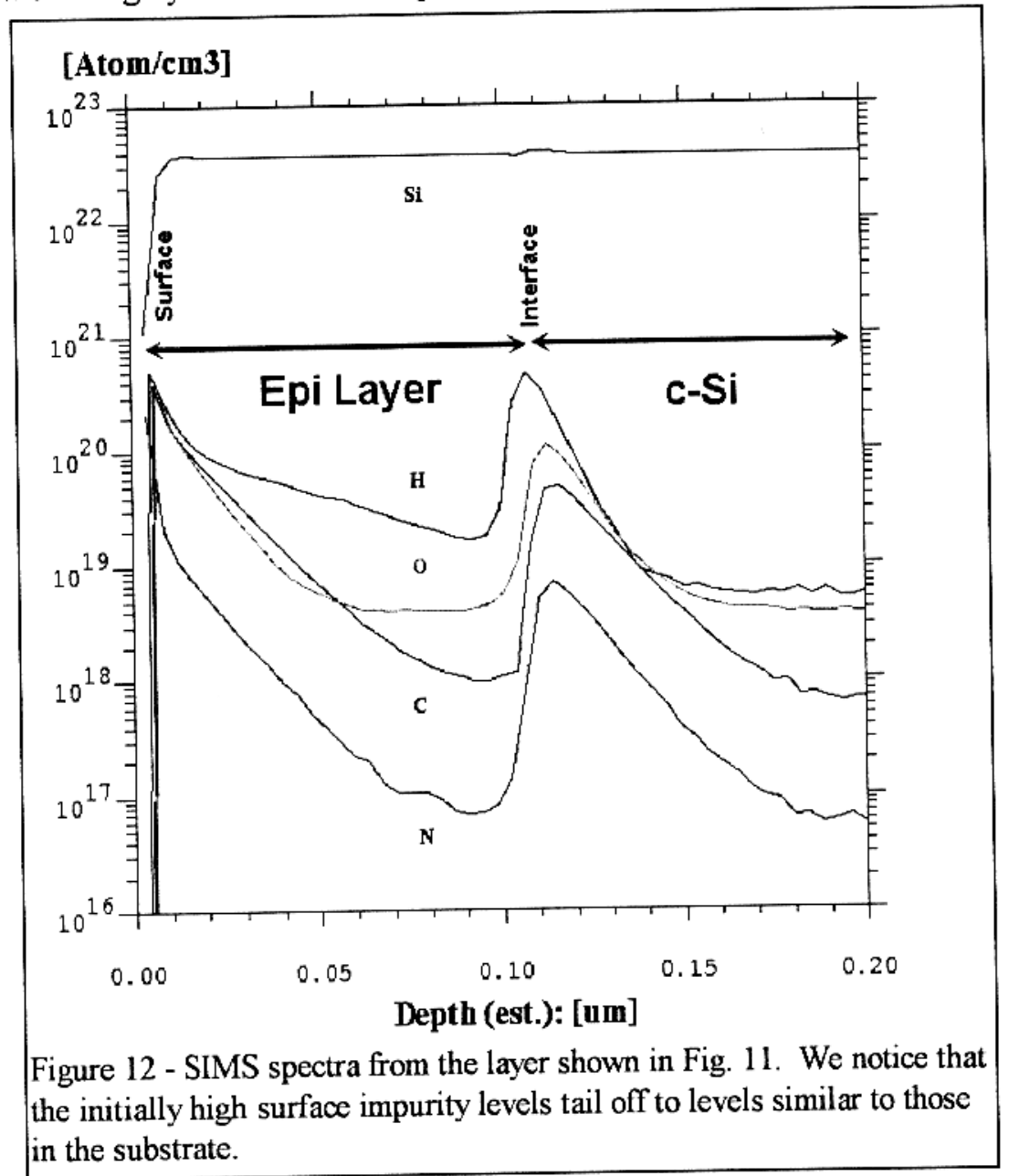

over $10^{20}$, seemed to turn amorphous within the first few hundred angstroms, possibly for reasons such as those put forth in the discussions of Fig. 9 and 10 . Only recently have we been able to use a dilute enough B source to attain meaningful results, and it is far to early for us to comment on these.

Other impurity levels in grown layers have been measured with SIMS as shown in Fig. 12. The high concentration of $\mathrm{H}$ at the interface we attribute to the $\mathrm{H}$ passivation of defects. The increased concentrations of these other interfacial contaminants may be explained in several ways. The first is that preceding every deposition the substrate carrier is removed from the system and exposed to air while substrates are loaded. This means that the level of impurities adsorbed onto the carrier is influenced by the ambient humidity, temperature, and overall environmental contamination. Obviously then, the in-film contamination levels can fluctuate more or less randomly from 
day to day, despite the experimentalist's best efforts to maintain process reproducibility. Indeed, these kinds of fluctuations are observed in SIMS data collected from samples produced under identical conditions, but at different times. Another factor influencing the overall contamination levels seen in the SIMS data, results from these samples being grown in a multi-use reactor. In the same day $\left(\mathrm{CH}_{3}\right)_{4} \mathrm{~B}$, highly concentrated $\mathrm{PH}_{3}$, and highly concentrated $\mathrm{B}_{2} \mathrm{H}_{6}$, as well as $\mathrm{CH}_{4}$, might all be flowing through the same reactor. This can have very interesting effects on $\mathrm{C}$ contamination and has already led to problems in carrying out proper doping experiments.

That's the bad news. The good news is that if we look at the impurity levels in the bulk of the film, we see that they are no worse that those of the substrate. Because surface contaminants cause initially high values which tail off, we identify the bulk levels in the cpitaxial layer as the lowest levels a studied impurity concentration reaches. This seem to indicate, that despite a lack of contamination control in the reactor, the bulk of the grown layer is at least as good as $\mathrm{Cz}-\mathrm{Si}$. Thus, we might expect contamination levels to improve a great deal, in a clean, controlled system. In other words, this process does not seem to carry with it any type of inherent impurity contamination. As an aside, it may be that the high level of interfacial impurities are at least partially responsible for the some of the observed crystallographic defects seen in our layers. It is conceivable that many of these defects might be eliminated if growth were commenced in a more controlled environment.

\section{Conclusions}

We have demonstrated the growth of high-quality homo-epitaxial $\mathrm{Si}$ at low temperatures using HWCVD. We have further discussed a variety of issues associated with this technique, and have presented an emerging phenomenological model for this type of epitaxy. We have shown that under some conditions, layers can be produced with device-quality electronic and crystallographic properties. Under other conditions, we have shown that this growth process is less well behaved and will require more work to understand and control. We have further demonstrated that dopants can be incorporated and activated during this growth process, despite the fact that at this time we have not been ablc to completely explore the extents of the dopant chemistry. SIMS data indicates that the overall impurity concentrations are reasonable for a system such as ours, and substantial reductions in these levels might be expected in a more controlled growth environment. Finally, we remark that high quality epitaxy has been observed despite the constraints of our current deposition system, which may be indicative of the potential HWCVD could have for LTE Si growth.

\section{Acknowledgments}

The authors wish to sincerely thank Alan Gallagher for many useful and insightful discussions. We would also like to thank the NREL a-Si team for their support during this work. This work has been funded by the United States Department of Energy under Contract No. DE-AC98-GO10337.

\section{References}

1. Mohajerzadeh, S., Sclvakumar, C. R., Brodie, D. E., Robertson, M. D. \& Corbett, J. M., Mat. Res. Soc. Symp. Proc. 388, 201-206 (1995).

2. Anthony, B., Breaux, L., Hsu, T., Bannerjee, S. \& Tasch, A., J. Vac. Sci. Technol. B. 7, (4):621(1989).

3. Mokler, S. M., Liu, W. K., Ohtani, N. \& Joyce, B. A. Appl. Phys. Lett 60, (18):2255-2257 (1992).

4. Chelly, R., Werckmann, J., Angot, T., Louis, P., Bolmont, D. \& Koulmann, J. J. ,Thin Solid Films 294, 84-87 (1997).

5. Ramana Murty, M. V. \& Atwater, H. A. ,Phys. Rev. B 49, (12):8483-8486 (1994).

6. Sedgwick, T. O., Agnello, P. D., Berkenblit, M. \& Kuan, T. S. Low-Temperature Selective Epitaxial Growth of Silicon at Atmospheric Pressure in an Ultra-clean System. Preprint 
7. Kobayashi, K., Fukumoto, K., Katayama, T., Higaki, T. \& Abe, H., 1992 Intl. Conf. on Solid State Devices and Materials 17-19 (1992).

8. Meyerson, B. inventor. Method and Apparatus for Low Temperature, Low Pressure Chemical Vapor Deposition of Epitaxial Silicon Layers. US. Pat. No., 5,298,452. (1994).1

9. Thompson, P. E., Twigg, M. E., Godbey, D. J. \& Hobart, K. D., J. Vac. Sci. Technol. B 11, (3):1077-1082 (1999).

10. Ramm, J., Beck, E., Dommann, A., Eisele, I. \& Kruger, D., Thin Solid Films 246, 158-163 (1994).

11. Violette, K. E., O'Neil, P. A., Ozturk, M. C., Christensen, K. \& Maher, D. M., ElectroChem. Soc.

Proc. 96-5, 375-379 (1999).

12. Varhue, W. J., Andry, P. S., Rogers, J. L., Adams, E., Kontra, R. \& Lavoie, M., Solid State

Technology 163-170 (1996).

13. Oshima, T., Sano, M., Yamada, A., Konagai, M. \& Takahashi, K., Appl. Surface Sci. 79/80, 215-219

(1994).

14. Ohmi, T., Hashimoto, K., Morita, M. \& Shibata, T. ,. J. Appl. Phys 69, (4):2062-2071 (1991).

15. Kasai, N. \& Endo, N. , J. Electrochem. Soc. 139, (7):1983-1987 (1999).

16. Lips, K. Low Temperature Homoepitaxial Si Growth using ECR Remote Plasma. Hans Meitner Institut:

(1999). Presentation of Work,

17. Eaglesham, D. J., Gossman, H. J. \& Cerullo, M., Phyiscal Review Letters 65, (10):1227-1230 (1990).

18. Molenbroek, E. \& Mahan, A. , J. Applied Physics 82, (4):1909-1917 (1998).

19. Molenbroek, E. C. Deposition of Hydrogenated Amorphous Silicon with the Hot Wire Technique. (1995).

University of Colorado. $1 \mathrm{p}$.

20. Doyle, J., Robertson, G. H., Lin, M. Z. \& Gallagher, A. , J. Appl. Phys 64, (6):3215-3222 (1988).

21. Sutoh, A., Okada, Y., Ohta, S. \& Kawabe, M., Jap. J. Applied Physics 34, (Part2, 10b):L1379-L1382 (1995).

22. Brogueira, P., Conde, J. P., Arekat, S. \& Chu, V., J. Appl. Phys. 78, (6):3776-3783 (1995).

23. Heintze, M., Zedlitz, R., Wanka, H. N. \& Schubert, M. B. , J. Applied Physics 79, (5):2699-2706 (1996).

24. Gupta, P., Colvin, V. L. \& George, S. M. , Physical Review B 37, (14):8234-8243 (1988).

25. Northrup, J., Phys. Rev. B Rapid Communications 44, (3):1419-1422 (1991).

26. Ishiazaka, A. \& Shiraki, Y., J. Electrochem. Soc. 133, (4):666-671 (1986).

27. Matson,R., Thiesen,J., Crandall,R.S., et. al., Materials Research Society. Spring Symp. V2.4. 1999

28. Taylor, M. E. \& Atwater, H. A. . Surface Science 127-129, 159-163 (1998).

29. Murty, M. V. R. \& Atwater, H. A., Surface Science 374, 283-290 (1997).

30. Boland, J. J. \& Parsons, G. N. , Science 256, 1304-1306 (1992).

31. Pearton, S. J., International Journal of Modern Physics 8, (9):1093-1158 (1994).

32. Johnson, N. M., Doland, C., Ponce, F., Walker, J. \& Anderson, G., Physica b 170, 3-20 (1991).

33. Boland, J., Surface Science 261, 17-28 (1992).

34. Niwano, M., Terashi, M. \& Kuge, J., Surface Science 420, 6-16 (1999).

35. CS Office Pro. (3.0) CambridgeSoft Corp.: Cambridge,Ma. CambridgeSoft Corp. (1999).

36. Heyman, J., Ager, J. W., E.Haller, E., Johnson, N. M., Walker, J. \& Doland, C. M., Phys Rev. B. 45, (23): 13363-13366 (1992).

37. Doris, B., Fretwell, J., Erskine, J. L. \& Bannerjec, S. K., Appl. Phys. Lett. 70, (21):2819-2821 (1997). 


\section{REPORT DOCUMENTATION PAGE}

Form Approved OMB NO. 0704-0188

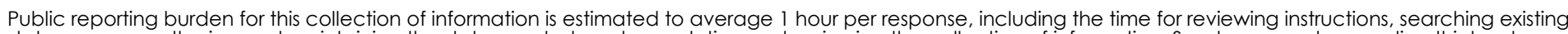

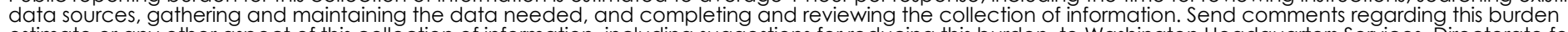

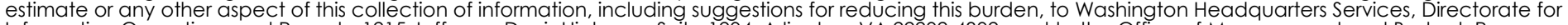

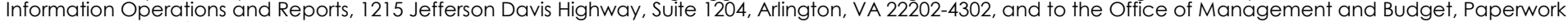
Reduction Project (0704-0188), Washington, DC 20503.

\begin{tabular}{|l|l|l|l} 
1. AGENCY USE ONLY (Leave blank) & $\begin{array}{l}\text { 2. REPORT DATE } \\
\text { August 1999 }\end{array}$ & $\begin{array}{l}\text { 3. REPORT TYPE AND DATES COVERED } \\
\text { Conference Paper }\end{array}$ \\
\hline
\end{tabular}

4. TITLE AND SUBTITLE

Growth of Homo-Epitaxial Silicon at Low Temperatures Using Hot Wire Chemical Vapor Deposition

6. AUTHOR(S)

J. Thiesen, K.M. Jones, R. Reedy, R. Crandall, E. Iwaniczko, and H. Mahan

\begin{tabular}{l|c} 
7. PERFORMING ORGANIZATION NAME(S) AND ADDRESS(ES) & 8. PERFORMING ORGANIZATION \\
National Renewable Energy Laboratory & REPORT NUMBER
\end{tabular}

1617 Cole Blvd.

Golden, CO 80401-3393

9. SPONSORING/MONITORING AGENCY NAME(S) AND ADDRESS(ES)

10. SPONSORING/MONITORING AGENCY REPORT NUMBER

CP-520-26365

11. SUPPLEMENTARY NOTES

12a. DISTRIBUTION/AVAILABILITY STATEMENT

National Technical Information Service

12b. DISTRIBUTION CODE

U.S. Department of Commerce

5285 Port Royal Road

Springfield, VA 22161

13. ABSTRACT (Maximum 200 words)

We report on the first known growth of high-quality epitaxial Si via the hot wire chemical vapor deposition (HWCVD) method. This method yields device-quality epitaxial $\mathrm{Si}$ at the comparatively low temperatures of $195^{\circ}$ to $450^{\circ} \mathrm{C}$, and relatively high growth rates of 3 to $20 \mathrm{v} / \mathrm{sec}$. Layers up to $4500-\mathrm{v}$ thick have been grown. These epitaxial layers have been characterized by transmission electron microscopy (TEM), indicating large regions of nearly perfect atomic registration. Electron channeling patterns ( ECPs) generated on a scanning electron microscope (SEM) have been used to characterize as well as optimize the growth process. Electron beam induced current (EBIC) characterization has also been performed, indicating defect densities as low as $5 \times 10^{4} / \mathrm{cm}^{2}$. Secondary ion beam mass spectrometry (SIMS) data shows that these layers have reasonable impurity levels within the constraints of our current deposition system. Both $\mathrm{n}$ and $\mathrm{p}$-type layers were grown, and $\mathrm{p} / \mathrm{n}$ diodes have been fabricated.

14. SUBJECT TERMS

photovoltaics ; homo-epitaxial silicon; hot wire chemical vapor deposition ; electron-beam induced current; electron channeling patterns

17. SECURITY CLASSIFICATION OF REPORT Unclassified
18. SECURITY CLASSIFICATION OF THIS PAGE Unclassified
15. NUMBER OF PAGES

19. SECURITY CLASSIFICATION OF ABSTRACT Unclassified 